\title{
BMJ Open Service evaluation of the GOALS family-based childhood obesity treatment intervention during the first 3 years of implementation
}

\author{
Paula M Watson, ${ }^{1}$ Lindsey Dugdill, ${ }^{2}$ Katie Pickering, ${ }^{3}$ Stephanie Owen, ${ }^{4}$ \\ Jackie Hargreaves, ${ }^{3}$ Leanne J Staniford, ${ }^{3}$ Rebecca C Murphy, ${ }^{1}$ Zoe Knowles, ${ }^{1}$ \\ $\mathrm{N}$ Timothy Cable $\mathrm{e}^{1,5}$
}

To cite: Watson PM, Dugdill L, Pickering K, et al. Service evaluation of the GOALS family-based childhood obesity treatment intervention during the first 3 years of implementation. BMJ Open 2015;5:e006519. doi:10.1136/bmjopen-2014006519

- Prepublication history and additional material is available. To view please visit the journal (http://dx.doi.org/ 10.1136/bmjopen-2014006519).

Received 2 September 2014 Revised 23 December 2014 Accepted 29 December 2014

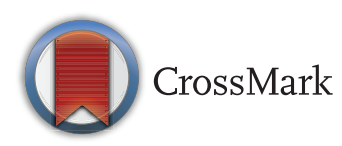

${ }^{1}$ Physical Activity Exchange, Research Institute for Sport and Exercise Sciences, Liverpool John Moores University, Liverpool, UK ${ }^{2}$ School of Health Sciences, University of Salford, Salford, UK

${ }^{3}$ Carnegie Faculty, Fairfax Hall, Leeds Beckett University, Leeds, UK ${ }^{4}$ Betsi Cadwaladr University Health Board, Wrexham, UK ${ }^{5}$ Aspire Academy, Qatar

Correspondence to Paula M Watson; p.m.watson@ljmu.ac.uk

\section{ABSTRACT}

Objectives: To evaluate the impact of the GOALS (Getting Our Active Lifestyles Started) family-based childhood obesity treatment intervention during the first 3 years of implementation.

Design: Single-group repeated measures with qualitative questionnaires.

Setting: Community venues in a socioeconomically deprived, urban location in the North-West of England.

Participants: 70 overweight or obese children (mean age 10.5 years, $46 \%$ boys) and their parents/carers who completed GOALS between September 2006 and March 2009.

Interventions: GOALS was a childhood obesity treatment intervention that drew on social cognitive theory to promote whole family lifestyle change. Sessions covered physical activity (PA), diet and behaviour change over 18 $2 \mathrm{~h}$ weekly group sessions (lasting approximately 6 months). A Template for Intervention Description and Replication (TIDieR) checklist of intervention components is provided.

Primary and secondary outcome measures: The primary outcome measure was child body mass index (BMI) z-score, collected at baseline, post-intervention and 12 months. Secondary outcome measures were child selfperceptions, parent/carer BMI and qualitative changes in family diet and PA (parent/carer questionnaire).

Results: Child BMI z-score reduced by 0.07 from baseline to post-intervention $(p<0.001)$ and was maintained at 12 months $(p<0.05)$. There was no change in parent/carer BMI or child self-perceptions, other than an increase in perceived social acceptance from baseline to post-intervention $(p<0.05)$. Parents/carers reported positive changes to family PA and dietary behaviours after completing GOALS.

Conclusions: GOALS completion was associated with small improvements in child BMI z-score and improved family PA and dietary behaviours. Several intervention modifications were necessary during the implementation period and it is suggested childhood obesity treatment interventions need time to embed before a definitive evaluation is conducted. Researchers are urged to use the TIDieR checklist to ensure transparent reporting of interventions and facilitate the translation of evidence to practice.

\section{Strengths and limitations of this study}

- This study reports ecologically valid data from a childhood obesity treatment intervention as it was delivered in practice.

- This is the first article to use the Template for Intervention Description and Replication (TIDieR) checklist to describe a childhood obesity treatment intervention, providing valuable information to assist policymakers and practitioners wishing to implement interventions in practice.

- As with many service evaluations, this study is limited by a lack of control group and a high attrition rate. It is not therefore known what change might have occurred without intervention or what impact the intervention had for those who did not complete.

\section{INTRODUCTION}

Currently $28 \%$ of children aged $2-15$ years in England are overweight or obese. ${ }^{1}$ Children who are obese face psychological ${ }^{2}$ and physical $^{3}$ health complications in the short term and are more likely to become obese adults. ${ }^{4}$ Since adult obesity is a key risk factor for lifestyle-related morbidity and mortality, ${ }^{5}$ it is important to develop effective interventions for treating obesity in childhood. Growing evidence supports a family-based approach to childhood obesity treatment that focusses on physical activity (PA), diet and behaviour change. ${ }^{6-11}$ Bandura's social cognitive theory ${ }^{12}$ provides a framework within which to understand the importance of family involvement in children's PA and dietary behaviours. The theory posits that behaviour interacts in an ongoing reciprocal manner with personal cognitions and the surrounding environment (triadic reciprocal causation). In children, the cognitions and behaviours of parents/carers also form part of this reciprocal interaction, ${ }^{13}$ as parents/carers play a key role in children's $\mathrm{PA}^{14}$ and dietary behaviours ${ }^{15}$ Therefore for 
children who are overweight to make healthy changes to their PA and diet, changes may also be required in their parents/carers' weight-related cognitions and behaviours.

Despite many childhood obesity treatment interventions using the term 'family-based', interventions vary in their level of parent/carer involvement. ${ }^{16}$ Some interventions have focused on parents/carers as the exclusive agents of change, ${ }^{17} 18$ others have promoted parent/carer support of the child's behaviour change ${ }^{719}$ and others have aimed to change both parent/carer and child behaviours simultaneously. ${ }^{20}{ }^{21}$ Despite the theorised importance of parental role-modelling in child behaviour however ${ }^{13}$ none of the aforementioned childhood obesity treatment interventions have involved practical PA sessions for both children and parents/carers together. Evidence from other health promotion settings shows joint parent/carer and child PA sessions can lead to improvements in children's PA levels, in preschool ${ }^{22}$ and primary-school ${ }^{23}$ age groups.

Children who are overweight often suffer low self-esteem, ${ }^{2}$ and one of the key reasons for parents/carers seeking treatment is to improve children's psychological well-being. ${ }^{24}$ Despite early concerns that an increased focus on weight, diet and PA might heighten weight-related concerns in children, ${ }^{25}$ recent reviews have found overall positive effects of childhood obesity treatment on self-esteem. ${ }^{6}{ }^{26}$ However, the evidence exploring the relationship between child weight change and self-esteem change remains inconclusive, with some studies ${ }^{27}$ showing an association between child body mass index (BMI) reduction and increases in self-esteem and others ${ }^{10}$ finding no association.

Although systematic review evidence supports a multidisciplinary family-based approach to childhood obesity treatment,${ }^{6}$ the controlled studies on which systematic reviews are based often lack the external validity and process information required for implementing interventions in practice. ${ }^{28}$ During recent years evidence from childhood obesity treatment interventions in the UK has increased rapidly, ${ }^{29-31}$ including qualitative insights into reasons for engagement, ${ }^{32} 33$ comparisons of parent, child and practitioner views ${ }^{24} 34$ and discussions of evaluation methods. ${ }^{35}{ }^{36}$ The poor reporting of intervention components in childhood obesity treatment studies however makes it difficult for decision makers to (A) assess transferability of interventions for their local context and (B) learn how interventions can feasibly be implemented in practice. ${ }^{37}$ Transparent reporting is particularly important during the early stages of a complex intervention, as challenges of delivery and implementation may impact the intervention's effectiveness. ${ }^{38}$ Use of tools such as the Template for Intervention Description and Replication (TIDieR) checklist ${ }^{39}$ have been advocated to support comparison between studies and facilitate the translation of evidence to practice.

The aim of the current paper is to evaluate a communitybased childhood obesity treatment intervention (Getting Our Active Lifestyles Started (GOALS) ${ }^{9} 3540$ 41) that drew on social cognitive theory ${ }^{12}$ to encourage healthy lifestyle changes for the whole family. The intervention included weekly practical PA sessions that involved children, parents/ carers, siblings and other family members. Previous findings from GOALS showed a positive association between child and parent/carer BMI reduction, whereby children attending GOALS were more likely to lose weight if their attending parent/carer also lost weight. ${ }^{9}$ This study will evaluate the impact of GOALS during the first 3 years of implementation, applying the TIDieR checklist $^{39}$ to describe intervention components. We will report post intervention (6-month) and 12-month outcomes, explore qualitative reports of lifestyle changes from parents/carers and assess the relationship between child BMI z-score change and child self-perception change.

\section{METHODS}

Participants

All families attending GOALS between September 2006 and March 2009 were invited to take part in the study. Children who attended GOALS but were not overweight, had obesity caused or exacerbated through medical conditions or syndromes, had severe learning disabilities or did not provide baseline data were excluded from the study. Where there was more than one eligible overweight child in the family only the data from the child who was referred to GOALS was included. Demographic information (age, gender, ethnicity, socioeconomic status by postcode, parent/carer relationship to child) was collected from participants at baseline.

\section{Intervention (GOALS)}

Between 2006 and 2013, Liverpool John Moores University, UK, was commissioned annually (through government grants, local authority and National Health Service (NHS) public health funds) to deliver a childhood obesity treatment service (GOALS) for socioeconomically deprived communities in Liverpool. The aim of GOALS was to support families to increase PA and make healthy dietary changes. GOALS was targeted at families with children aged 4-16 years who were obese (BMI $\geq 98$ th centile according to the UK 1990 BMI reference charts ${ }^{42}$ ), although children were occasionally included who were overweight (BMI $\geq 91$ st centile). Minimal family unit was one child plus one parent/ carer, although siblings and other family members were encouraged to attend.

Twenty-two GOALS interventions were delivered between September 2006 and March 2009. One intervention was excluded from the study because the children received an additional weekly PA session, leaving 21 eligible cohorts. Table 1 provides key intervention details, mapped to the TIDieR checklist. ${ }^{39}$ The intervention framework in table 1 remained constant throughout the study. However, the implementation process presented several delivery challenges, and some modifications were necessary. These included changes to recruitment and assessment processes, delivery venues, staff roles, counselling support, provision of childcare for younger siblings, 
Table 1 GOALS intervention details

\begin{tabular}{|c|c|}
\hline Item & Description \\
\hline Name (1) & GOALS \\
\hline Why (2) & $\begin{array}{l}\text { The aim of GOALS was to promote a healthy weight trajecto } \\
\text { on supporting the whole family to become more physically ac } \\
\text { Owing to the lack of available evidence when GOALS was fo } \\
\text { methodology was used to develop and evaluate the interven } \\
\text { process). The whole family, multidisciplinary approach is sup } \\
\text { Intervention topics were informed by social cognitive theory } \\
\text { causation between environmental, behavioural and cognitive } \\
\text { self-efficacy of children and parents/carers for PA and health } \\
\text { experiences, reciprocal modelling opportunities, and positive } \\
\text { details). } \\
\text { Dietary objectives: } \\
\text { To encourage families to: } \\
\text { Eat a healthy balanced diet } \\
\text { Reduce portion sizes } \\
\text { Consume fewer processed foods } \\
\text { Cook more meals from fresh } \\
\text { Increase fruit and vegetable intake } \\
\text { Replace snacks high in fat and sugar with healthier } \\
\text { alternatives } \\
\text { Reduce the amount of salt and sugar added to food } \\
\text { and drink } \\
\text { Reduce the frequency of takeaways } \\
\text { Increase water consumption } \\
\text { Read food labels and become more aware of what they } \\
\text { are eating }\end{array}$ \\
\hline
\end{tabular}

What-procedure (4)

Children were referred to GOALS through multiple routes, including self-referral in response to promotional activities (eg, press articles, leaflets, whole school letters) and referral from health professionals in primary or secondary care. In addition from April 2007 children aged 9-10 years were recruited via letters to their parents/carers following participation in a local health and fitness programme in schools (SportsLinx ${ }^{44}$ ).

Approximately 1 -week before the intervention each family attended a 'lifestyle assessment' with an intervention delivery staff member. The purpose of these sessions was to build rapport with families, complete paperwork such as consent and monitoring forms, and to gather information about the family's PA and dietary habits through an informal interview.

The intervention sessions focused on diet (Fun Foods), PA (Move It) and behaviour change and well-being (Target Time)

Fun Foods: Aimed to equip families with the knowledge and practical skills to incorporate a healthy balanced diet into their lifestyle, based on the NHS Choices eatwell plate. ${ }^{45} \mathrm{~A}$ range of classroom-based and practical sessions addressed topics such as portion sizes, reading food labels and healthy snacking. Families were provided with practical opportunities to develop their cooking skills, and to try out new recipes and foods.

Move It. Involved a practical PA session with the aim of improving self-efficacy to be physically active outside the weekly sessions. Sessions aimed to engage the whole family, with a focus on enjoyment and personal achievement rather than competition.

Target Time: Supported families to make their lifestyle changes easier through the use of multiple behaviour change techniques (full description of techniques used is available in online supplementary resource 1) and through promoting and enhancing psychosocial well-being. Classroom-based sessions focused on topics such as hunger and craving, raising self-esteem, dealing with bullying and parental role-modelling. Each week families were supported to set small, realistic goals focused on changing their PA and dietary behaviours outside of the structured GOALS sessions.

Specific content evolved according to ongoing evaluation. An example timetable is available from PMW (p.m.watson@ljmu.ac.uk).

What-materials (3)

Sessions were supported by a number of informative materials, such as parent/carer and child handbooks, personal log books to track progress and a GOALS cookbook containing healthy recipes to cook at home. Delivery staff were supplied with weekly session plans. Copies of all informative materials are available from PMW (p.m.watson @ljmu.ac.uk). Growth charts and BMI charts were used to monitor child height and weight (available from http://www.childgrowthfoundation.org/). 
Table 1 Continued

\begin{tabular}{ll}
\hline Item & Description \\
Who provided (5) & GOALS was designed, delivered and evaluated by a team from Liverpool John Moores \\
operationally led by the project manager/principal researcher (PMW). The team consis \\
staff member and several sessional staff for each section (Fun Foods, Move It, Targe \\
and sessional staff were involved in delivering the intervention. Senior staff held postg \\
qualifications in public health nutrition (SB-Fun Foods lead), exercise physiology (KP \\
health psychology (JH-Target Time lead to April 2008) and sport and exercise psyc \\
Time lead from September 2008) and were responsible for developing the intervention \\
sessions and supervising sessional staff in the delivery of sessions. Sessional staff wer \\
range of backgrounds and were employed part-time to deliver the intervention. For the \\
following skills and attributes were pre-requisites: \\
- Minimal vocational qualification for their subject area \\
- An interest in promoting healthy lifestyles \\
- Interpersonal skills and the ability to engage groups of different ages and abilities \\
- Experience of delivering activities to groups of children and/or families.
\end{tabular}

How (6)

Interventions were delivered to groups of families, arranged where possible by child age (eg, 4-7 years, 8-11 years, 12-16 years). Groups ranged from 5-12 families at baseline. Some sessions included parents/carers and children together, but topics involving sensitive discussion (eg, dealing with bullying) or aimed specifically at parents/carers (eg, meal planning) were delivered to children and/or parents/ carers separately.

Where (7)

Sessions were delivered after school in primary and secondary schools across Liverpool. Liverpool is a city in the north-west of England with approximately 470780 residents ${ }^{46}$ and high levels of socioeconomic deprivation. ${ }^{47}$ Despite indications that childhood obesity rates have begun to plateau, ${ }^{48}$ prevalence of childhood obesity in Liverpool remains higher than the national average with $28.6 \%$ of $4-5$-year-olds and $39 \%$ of $10-11$-year-olds overweight or obese. ${ }^{49}$

When and how much (8)

Sessions lasted for $2 \mathrm{~h}$ and ran once a week after school (usually 17:30-19:30 or 18:00-20:00) during term-time only. During year 1 (September 2006-March 2007), contact varied between 17, 18 and 19 sessions. During years 2 and 3 (April 2007-March 2009), the intervention included 18 sessions. Owing to the term-time only delivery, interventions varied in duration depending on whether they started during autumn/winter (approximately 5 months) or during spring/summer (approximately 6 months due to the long summer holiday break)Families were invited to individual follow-up sessions 9 months (from April 2007 only) and 12 months after they had started GOALS. These sessions lasted approximately $45 \mathrm{~min}$ and involved a progress review and height and weight measurements.

Tailoring (9)

Each family was assigned a personal mentor who they met with every few weeks to track their progress. The use of social cognitive theory allowed staff mentors to set weekly goals with families that focused on either the home environment, parental behaviours/cognitions or child behaviours/cognitions, depending on the underlying cause of the target behaviour. For example, the goal for a family where the child was overeating in response to being bullied might focus on developing coping skills for the child (child cognitions), whereas the goal for a family where the child was overeating because their portions were too large might be for the parent/carer to serve appropriate child portion sizes (parent/carer behaviour).

Provision was made for childcare of younger siblings where required.

Taxis were provided for families without transport in 8 of the 21 intervention cohorts.

How well-planned and actual $(11,12)$
During the first year, reflective staff meetings were held weekly to ensure the intervention was delivered as intended and to agree actions for the following week. Staff completed a written evaluation after each session to note what worked well, challenges they had faced and ideas for improvement. During the later stages, meetings continued on a six weekly basis with regular session visits from the project manager. Regular training ensured the GOALS ethos and core framework was understood and practised by all staff.

Numbers in parentheses refer to the item number on the TIDieR checklist. ${ }^{39}$

GOALS, Getting Our Active Lifestyles Started; PA, physical activity; TIDieR, Template for Intervention Description and Replication.

support with transport to venues and support for children who had finished the intervention. Full details of these delivery issues and resulting modifications are provided in table 2 (TIDieR item 10).

\section{Outcome measures}

BMI (collected from children and parents/carers at baseline, post-intervention and 12 months)

Height and weight measures were taken by PMW and senior staff (KP, SO, JH and LJS). Weight was recorded to the nearest $0.1 \mathrm{~kg}$ using a Tanita WB/100MA floor scale. Height was recorded to the nearest $0.1 \mathrm{~cm}$ using a portable Leicester Height Measure. To control for measurement error staff took two height measures and calculated the mean. If these two measures differed by $1 \%$ or more a third measure was taken and the median used. BMI was calculated using the equation weight $(\mathrm{kg}) / \mathrm{height}$ $(\mathrm{m})^{2}$. To account for change in children's ages from baseline, BMI was converted to z-scores based on the $1990 \mathrm{UK}$ Growth Reference curves ${ }^{42}$ using LMS Growth Software. ${ }^{53}$ 
Table 2 Modifications to the GOALS delivery mechanisms during the study period and lessons learned

\begin{tabular}{|c|c|}
\hline TIDieR item & Modification \\
\hline $\begin{array}{l}\text { What- } \\
\text { procedure (4) }\end{array}$ & $\begin{array}{l}\text { During year } 1 \text { every child was assessed for } \\
\text { underlying causes of obesity and comorbidities by } \\
\text { a community paediatrician. In year } 2 \text {, this was } \\
\text { replaced with an assessment with a school nurse } \\
\text { and later a self-completion form by the parent/carer } \\
\text { with recommendations to visit the family GP before } \\
\text { starting the intervention. }\end{array}$ \\
\hline
\end{tabular}

Rationale and lessons learned

The available guidelines for treating childhood obesity recommended all children with a $\mathrm{BMI} \geq 99$.6th centile be referred to hospital or community paediatric consultants before treatment was considered ${ }^{50}$ and a medical assessment be undertaken of presenting symptoms and underlying causes of overweight and obesity, comorbidities and risk factors, and growth and pubertal status. ${ }^{51}$ As the majority of children registering for GOALS had a BMI $\geq 99.6$ th centile, assessment by community paediatricians proved a time-consuming and costly arrangement, and research suggested these assessments may not be necessary for all obese children. ${ }^{52}$ The protocol was therefore replaced by an assessment with a school health practitioner and later a self-completion form by the parent/carer, in which they were signposted to the GP.

Where (7) Year 1 interventions were delivered in primary $(n=4)$ and secondary schools $(n=3)$. Year 2 and 3 interventions were delivered in secondary schools only.

Who provided

(5)

Who provided (5)
During year 1, Fun Foods was led by community dietitians (theory-based sessions) and community food workers (practical sessions) employed by the NHS in Liverpool. From year 2, the employment of all Fun Foods staff was transferred to Liverpool John Moores University. A public health nutritionist delivered the theory-based sessions and food workers continued to deliver practical elements. In September 2008 (mid-year 3) all food workers were trained to be 'nutrition mentors', responsible for the delivery of both theory-based and practical sessions with ongoing training and supervision from the public health nutritionist.

A qualified counsellor began working with GOALS in February 2007 (end of year 1) to provide additional support for children and families where appropriate.
Owing to the multidisciplinary nature of the intervention, each site required space for PA, facilities for cooking and classrooms for general activities. Primary schools were rarely open during evening hours (and thus incurred costs for site management) and cooking facilities were often limited to the school kitchens. By contrast, secondary schools provided ideal space for group cooking sessions in food technology rooms and were often open during the evening for adult education classes (thus allowing free access).

Little guidance was available outlining the skills required for delivery of healthy eating sessions in the community. Since the intervention focused on general healthy eating advice rather than individually-prescribed diets, it was established that a public health nutritionist possessed the relevant skills for supervision and quality assurance of the Fun Foods element of the intervention.

The group session provided little opportunity for children or families to discuss personal issues that may have been affecting their lifestyle change (eg, if children were being bullied). The GOALS lifestyles counsellor provided an impartial source of support for children or families who needed to talk something through that went beyond the remit of the GOALS staff. Several different ways of working were explored, ranging from informal drop-ins during the weekly session, group sessions about feelings, and fixed appointment times for families either during or outside of the weekly session. While the support was deemed beneficial for families, it proved difficult to sustain financially and the counsellor's involvement ceased a short time after the study period. 
Table 2 Continued

\begin{tabular}{ll}
\hline TIDieR item & Modification \\
\hline Tailoring (9) & $\begin{array}{l}\text { During years } 1 \text { and 2, a mobile crèche was } \\
\text { provided on site for younger siblings (if required). } \\
\text { During year 3, younger siblings were included in } \\
\text { the main programme. }\end{array}$
\end{tabular}

Tailoring (9) The number of interventions in which taxis were provided for families increased with each year $(1 / 7$ in year $1 ; 3 / 7$ in year $2 ; 4 / 7$ in year 3$)$.

\section{Rationale and lessons learned}

To allow whole families to attend, it was important provision was made for the childcare of younger siblings. Therefore a free créche was provided for families at the intervention site. However the mobile créche proved costly given the small number of children who used it, and children often expressed a wish to join in the main group's activities. The option of arranging local child-minders was explored but the families concerned were reluctant to leave their children with an unknown adult. Therefore the most appropriate solution was to accommodate young children within the main session, with an allocated staff member to take them aside for age-appropriate activities where necessary.

As it was not possible to provide intervention sites in every district of the city, consideration was given to the provision of transport for families who lived further afield. Several options were explored, including reimbursement of public transport expenses for families without a car and arrangement of taxis to and from sessions. It was however a challenge to develop objective criteria for offering these services and there was some concern the arrangement of taxis hindered the lifestyle change process for families. Financial support for transport was ceased after the study period, and staff instead supported families to identify appropriate public transport solutions.

When and A family-based weekly PA session for 'GOALS how much (8) graduates' was piloted between May 2007 (start of year 2) and July 2008 (mid-year 3).
Families expressed a wish for continued support beyond the 18-week intervention. However, sessions later ceased due to poor attendance and pressure to allocate financial resources to the main intervention.

Numbers in parentheses in the first column refer to the item number on the TIDieR checklist. ${ }^{39}$

Year 1=September 2006-March 2007; year 2=April 2007-March 2008; year 3=April 2008-March 2009.

BMI, body mass index; GOALS, Getting Our Active Lifestyles Started; GP, general practitioner; TIDieR, Template for Intervention Description and Replication.

Child self-perceptions (collected from children over 8 years at baseline, post-intervention and 12 months)

Child self-perceptions were measured using the SelfPerception Profile for Children (SPPC) ${ }^{54}$ The SPPC is a 36-item validated questionnaire consisting of six subscales measuring global self-esteem plus five specific domains of self-esteem in children. The SPPC is validated for use in children aged over 8 years and has acceptable internal consistency reliabilities for all six subscales (Cronbach's $\alpha$ range $0.71-0.86$ ). To reduce participant burden, four subscales that have been shown to change through healthy lifestyle intervention ${ }^{26}$ were used in the current study (Social acceptance, Athletic competence, Physical appearance, Global self-esteem), yielding a questionnaire with 24 items in total (6 in each subscale).
Changes in PA and diet (collected from parents/carers who attended after April 2007 at post-intervention and 12 months)

Parents/carers completed a questionnaire containing four qualitative feedback items that explored changes in their own PA levels, their child's PA levels, their child's confidence and their family's diet. At 12 months, parents/ carers were also asked questions about their facilitators and barriers to change. Full questionnaire schedules are available in online supplementary resource 2 .

\section{Analysis}

To account for clustering of children within intervention cohorts, data were first entered into MLwiN V.2.24 (Centre for Multilevel Modelling, Bristol, 2011) to explore the variance contributed by between-cohort differences 
(comparison of a two-level model (time, child) with a three-level model (time, child, cohort), BMI z-score change as the outcome variable). As inclusion of cohort as a random variable did not improve the fit of the model, data were treated as independent and pooled for analysis in SPSS V.17 (SPSS Inc., 2008). Outcome data is presented for complete cases only. Data was tested for normality using the Kolmogorov-Smirnov test. Paired samples t tests (normally distributed data) and Wilcoxon signed rank tests (non-parametric data) were used to assess withinsubjects change from baseline to post-intervention, and from baseline to 12-month follow-up. Pearson correlations were used to measure relationships between child BMI z-score change and child self-perception change, and child BMI z-score change and age. Independent $t$ tests were used to compare results by gender. Responses to the feedback questionnaires were first coded as 'improved', 'unchanged' or 'declined' (stage 1), then analysed against the GOALS intervention objectives (see table 1) with subsequent inductive analysis to allow new themes to emerge (stage 2). To enhance the credibility of findings, stage 1 analysis was carried out independently by two members of the research team (PMW and RCM). Inter-rater agreement ranged from 0.80 to 0.91 . Stage 2 analysis was carried out by PMW, followed by a process of peer scrutiny and discussion to reach a consensus on the final themes.

\section{RESULTS}

\section{Baseline characteristics}

One hundred and forty-three families were included in the study (143 children (63 boys), 168 parents/carers). According to the 2007 indices of deprivation, ${ }^{55} 92 \mathrm{fam}$ ilies lived within the $10 \%$ most deprived neighbourhoods in England, 34 in the 11-50\% most deprived and 17 in the $50 \%$ least deprived. Mean child age was 10.4 \pm 2.2 years (range 4.7-16 years) and mean BMI z-score was $3.0 \pm 0.57$ (range 1.53-4.73). One hundred and eight children were super obese (BMI $\geq 99.6$ th centile), 29 children were obese (BMI $\geq 98$ th centile) and 6 children were overweight (BMI $\geq 91$ st centile) according to the 1990 UK Growth Reference data. ${ }^{42}$ Ethnicity data was provided for 79 children, 67 of whom were white-British, 2 white-other background, 3 mixed race, 3 black-British, 1 Asian and 3 from other backgrounds. While this ethnic profile is representative of the Liverpool population, it is less diverse than the national population in England and Wales, where there is a higher proportion of ethnic minority groups. ${ }^{46}$ Of the 168 parents/carers taking part, 120 were mothers, 34 fathers, 13 other relations ( 7 grandmothers, 3 adult siblings, 1 aunt, 2 other carers) and 1 unknown.

\section{Participant flow through study}

Seventy-four families (74 children, 81 parents/carers) completed the intervention (at least $50 \%$ attendance and still attending at the end of the intervention) (see figure 1). Median attendance for these families was
83.3\%. Families were included in the complete case analysis if the overweight child in the family had complete baseline and post-intervention (6-month) BMI data. If a child was excluded from the analysis, their parents/ carers were also excluded. Of the 74 children who completed, 3 were excluded ( 2 had no post-BMI data, the third lost weight due to a medically prescribed diet), leaving 71 children for analysis. One further child's data was removed, as his BMI z-score change from baseline to post-intervention $(-0.71)$ was over 3 SDs greater than the sample mean. Therefore the complete case analysis included 70 children (32 boys), with 58 parents/carers (43 mothers, 13 fathers, 2 other) providing complete baseline and post-intervention BMI data. One father was excluded due to following a very low calorie diet plan independent of GOALS, leaving 57 parents/carers in the BMI analysis (6 healthy weight, 24 overweight, 27 obese). The characteristics of the 70 complete child cases were comparable with those of the whole cohort at baseline, with a mean age of $10.5 \pm 2.1$ years and a mean BMI z-score of $3.02 \pm 0.60$.

\section{Child outcomes}

Table 3 shows the BMI z-score and self-perception scores for children at baseline, post-intervention and 12 months. There was a significant decrease in BMI z-score from baseline to post-intervention $(-0.07$, $\mathrm{p}<0.001)$ that was maintained at 12 months for the children who attended follow-up (baseline to post-intervention $-0.09, \mathrm{p}=0.004$; baseline to 12 months -0.09 , $\mathrm{p}=0.041$ ). Forty-five children provided complete baseline and post-intervention self-perception data (exclusions were due to incomplete questionnaires $(n=10)$, age under 8 years $(\mathrm{n}=6)$ and absence when the questionnaires were completed $(n=9))$. There were small improvements in all self-esteem domains from baseline to postintervention, though the only change to reach significance was in the social acceptance domain (0.26, $\mathrm{p}=0.028$ ). There were no significant differences in child outcomes by gender or age.

\section{Correlations between BMI z-score and self-perceptions}

There were no correlations between baseline BMI z-score and baseline self-perceptions, or between BMI z-score change and self-perception change at either post-intervention or 12 months. However, the correlation between baseline BMI z-score and perceived social acceptance change from baseline to post-intervention approached significance $(\mathrm{r}=0.288, \mathrm{p}=0.055)$, suggesting the most obese children experienced the greatest increase in perceived social acceptance. There were also significant correlations between baseline to post-intervention BMI z-score change and baseline to 12-month self-perception change in two domains (global self-esteem, $\mathrm{r}=-0.433, \mathrm{p}<0.05$; physical appearance, $\mathrm{r}=-0.423, \mathrm{p}<0.05)$ and correlations that approached significance in the other two domains (social acceptance, $\mathrm{r}=-0.380, \mathrm{p}=0.061$; athletic competence, $\mathrm{r}=-0.390, \mathrm{p}=0.060)$. This indicates the children 


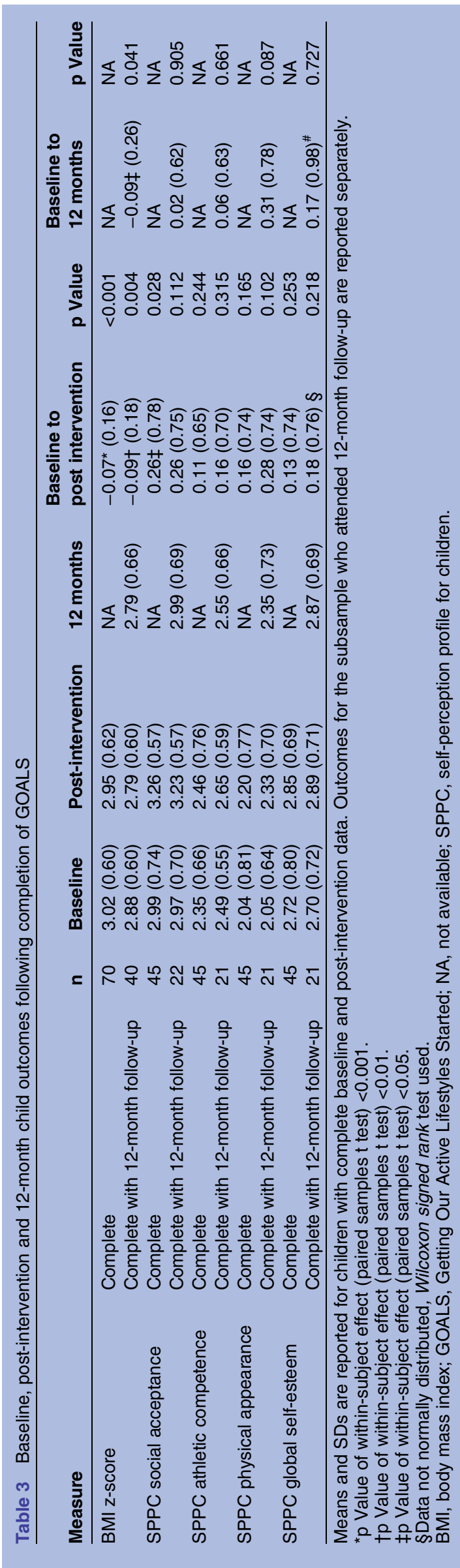

who lost the most weight during the intervention had the most improved self-perceptions at 12 months.

\section{Parent/carer outcomes}

Median BMI did not change between baseline (29.42, IQR 27.10-35.19, $\mathrm{n}=57$ ), post-intervention (29.89, IQR 27.12-35.24, $\mathrm{n}=57$ ) and 12 months (30.91, IQR 26.73$34.63, \mathrm{n}=33)$.

\section{Parent-reported/carer-reported changes in family PA and diet}

Of 56 parents/carers who completed GOALS after April 2007, 44 completed questionnaires post-intervention and 19 completed questionnaires at 12 months. In some families (two at post-intervention, two at 12 months) two parents/carers completed a questionnaire. Therefore, for items related to child or family changes the data from both parents/carers was either combined (where there was agreement) or excluded (where there was disagreement).

\section{Post-intervention changes}

A summary of the post-intervention questionnaire responses with example quotes is provided in table 4 . None of the parents/carers reported declines in their family's PA and dietary behaviours, although there were a few cases where no change was reported (six for parent/ carer PA levels, one each for child PA levels, child confidence and family diet). Improvements to parents/carers' own PA levels focused mostly on structured exercise and walking, whereas in their children they reported examples related to sport participation, active transport, exercise and active play. The majority of parents/carers commented on their child's improved confidence and increased willingness to get involved in PA, although some noted their child still lacked confidence outside of the GOALS setting. In terms of diet, many responses focused on a healthy balanced diet in general and an increase in fruit and vegetable intake. Examples of healthy choices were provided, such as switching to healthier varieties of foods, introducing new foods or removing high fat foods. Several parents/carers described their child's increased willingness to try new foods.

\section{Twelve-month changes}

Positive changes were reported for all children's PA levels, though in one case this was a delayed change not attributed to GOALS ("my child's activity levels have gone up since moving into high school"). Improvements in child confidence were maintained for all families (eg, "[my son] is more confident in himself and I feel the change he has made will be forever"). Maintenance levels were slightly lower for parent/carer PA (13/19) and family dietary changes (11/17); although there were a further three parents/carers who reported keeping up some, but not all, of their dietary changes (eg, "We have changed a lot of eating habits, but sometimes will fall back and have to start again"). The parents/carers who had maintained changes provided 
Figure 1 Participant flow through study (BMI, body mass index; GOALS, Getting Our Active Lifestyles Started).

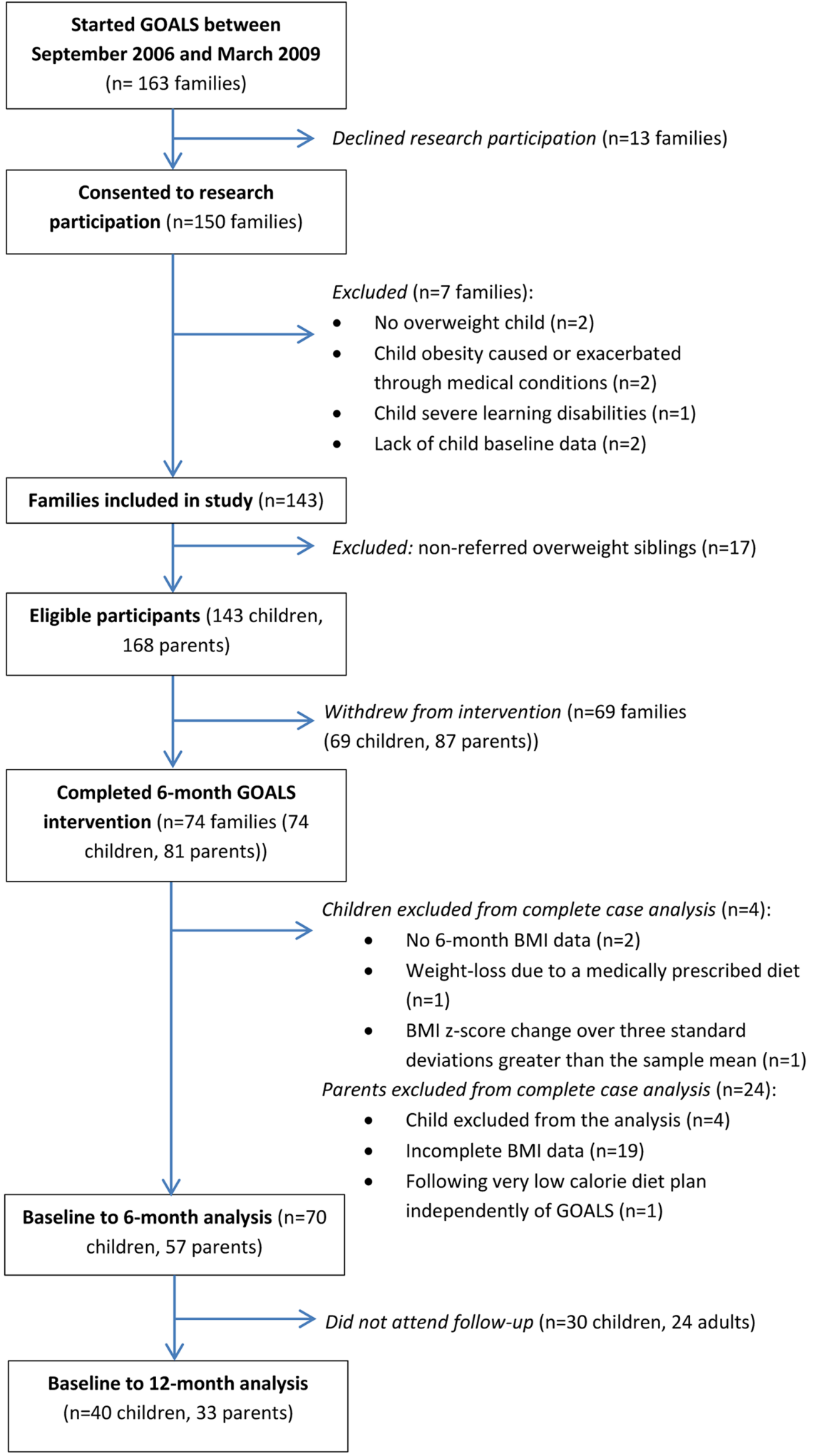

examples of healthy behaviours that had become a way of life for them (eg, "we now think before we eat 'rubbish' and our diet has improved vastly without too many big changes and it's become a way of life"), described the acquisition of coping skills to prevent relapse (eg, "I can feel when I'm getting lazy and I up my walking") and the formation of healthy routines (eg, "we always do an activity as a family once a week").
In response to the question about facilitators, parents/ carers commented on the importance of education (eg, "GOALS helped me in choosing healthy options and checking labels on food"), small attainable changes (eg, "the idea that small changes that can be maintained more easily can make a difference to your weight and shape"), making exercise fun (eg, "showing you how to enjoy yourself with your family during exercise") and coping skills for 
Table 4 Post-intervention parent-reported/carer-reported changes in family PA and diet

\section{Questionnaire item responses I U D NA Example quotes (category in parentheses)}

Parent/carer PA levels $41 \quad 346-1$ "[I] regularly attend the gym" (I)

"I am a lot more active, I always walk instead of getting a taxi" (I)

"[My PA levels have] stayed the same" (U)

"Doing Move It has made me realise just how unfit I really am" (NA)

Child PA levels

"[My child is] more active, swimming has improved, little more running" (I)

"[My son] now goes to cricket, football" (I)

"Walk home from school most nights"(I)

"[My daughter] plays more physical games" (I)

"My son tries much harder now without giving up too soon" (I)

"[My child] has increased [PA] to some degree, but have found it difficult to fit in around school/homework" (I) "[My child's PA levels are] the same" (U)

Child confidence $\quad 40 \quad 361-3 \quad$ "[My grandson] doesn't seem to worry so much now about his weight and looks more confident" (I)

"[My daughter] is more positive and confident towards exercise" (I)

"[My son] has become more involved and will try most things" (I)

"My son has always been confident so there has been no change" $(U)$

"My child is positive when he is at GOALS, but still not so in school and around people he doesn't really know" (NA)

Family diet

40

$381-1$ "[We make] a lot more healthier choices at the same cost as before" (I)

"[We] eat far more fruit and veg" (I)

"Sausage rolls or pies are now a definite "no no"' (I)

"Kids more adventurous with trying new foods" (I)

"Not much change as we have always ate fairly healthy" (U)

"I have been conscious of eating healthily for some time, but found it difficult to control what [my son] ate outside" (NA)

Eligible responses represent the number of responses for each item after accounting for agreement/disagreement between parents/carers from within the same family. For the parent/carer PA levels item, only 41 responses were provided ( 3 were left blank). Example quotes are provided to illustrate the range of responses for each item in the I category, plus single examples for the $U$ and NA categories where applicable.

$\mathrm{D}$, declined; I, improved; NA, uncoded (was not possible to deduce from the response whether there was any change); PA, physical activity; U, unchanged. 
maintaining change (eg, "the GOALS methods kick in when I start to feel unhealthy"). Parents/carers also mentioned the enthusiasm and encouragement from staff, and specific sessions that had helped them such as the portion sizes and practical cooking sessions.

As most of the families had maintained some changes, very little information was provided on barriers. Those who had relapsed said they had done so because of poor health, lack of time/planning and other commitments. One parent who had struggled to keep up his PA levels noted the GOALS group session finishing had been a big challenge.

\section{DISCUSSION}

The aim of this paper was to evaluate the impact of the GOALS family-based childhood obesity treatment intervention during the first 3 years of implementation, applying the TIDie $\mathrm{R}^{39}$ checklist to describe intervention components. Children completing GOALS demonstrated improvements in BMI z-score that were maintained at 12-month follow-up. There was also a small improvement in perceived social acceptance that was most marked in the children with the highest baseline BMI z-score, and a moderate correlation between BMI z-score reduction during the intervention and improved self-perceptions at 12 months. While there was no change in parental BMI, parents/carers reported positive changes to their own and their child's PA and diet.

The mean BMI z-score change $(-0.07)$ for children completing GOALS is consistent with the outcomes of other evaluations carried out in a service-delivery setting, ${ }^{10}{ }^{56}$ yet smaller than that reported in randomised controlled trials (RCTs) of community-based childhood obesity treatment interventions in the UK. ${ }^{71}$ While discussion surrounds what constitutes a clinically important BMI z-score reduction, ${ }^{57}$ evidence shows that even small reductions in BMI z-score are associated with positive improvements to cardiovascular risk factors in obese children ${ }^{58} 59$ and as such any improvement in BMI z-score should be viewed as a positive intervention outcome. ${ }^{60}$

While reviews have found overall positive effects of childhood obesity treatment on self-esteem, ${ }^{6}{ }^{26}$ authors have expressed concern that the increased focus on weight-related behaviours could have adverse effects on children's self-perceptions. ${ }^{25}$ Quantitative data in this study showed little change in children's self-perceptions, although parents/carers did report qualitative increases in children's confidence. While children's perceived social acceptance scores were comparable with a UK sample of mixed-weight children, ${ }^{61}$ their scores on the perceived athletic competence and physical appearance scales remained low. It is important that obesity treatment interventions help parents/carers understand how they can promote a healthy body image in children, for example through focusing on healthy behaviours rather than weight and encouraging children to adopt an identity that goes beyond physical appearance. ${ }^{62}$
While child weight loss has previously been linked to self-esteem improvements, ${ }^{27}$ it is not clear whether child weight loss improves self-esteem or improved self-esteem facilitates child weight loss, or both. ${ }^{26}$ In the present study BMI z-score change during the intervention was not linked to self-perception changes over the same period (as also found in ref. ${ }^{10}$ ), but was inversely associated with self-perception change from baseline to 12-month follow-up. The fact that this relationship was found in only one direction (ie, there was no correlation between self-perception change during the intervention and baseline to 12-month BMI z-score change) suggests that weight loss in the short term may lead to improvements in children's self-perceptions over the longer term.

A key challenge for childhood obesity treatment is the transition from the safe and supportive group environment to long-term behaviour change at home. ${ }^{34}$ Although most parents/carers reported positive changes to PA and diet that were maintained after finishing GOALS, many parents/carers spoke of the tendency to fall back into old habits from time to time. Such cycles of change are wellestablished in the health behaviour literature, ${ }^{63}$ and data from the current study suggests the skills learned at GOALS were used as an effective coping mechanism to prevent full relapse. As theorised by the social cognitive framework on which GOALS was based, ${ }^{12}{ }^{13}$ family support may be important in maintaining healthy behaviours. Previous research from childhood obesity treatment shows the most successful families are those who work together to achieve healthy lifestyle changes. ${ }^{9}{ }^{24}$ GOALS placed a strong emphasis on family involvement through inclusive PA sessions for children, parents/carers and siblings and a focus on changing the whole family's lifestyle. The success of this whole family engagement was evidenced by the proportion of children who attended with at least two other family members (approximately 60\%). Although the whole family focus did not result in a change in parental BMI (possibly due to the lack of emphasis on parental weight loss), the qualitative data suggested parents/carers made changes to their own PA levels and to the whole family's dietary habits. The potential for social desirability in these parent/carer reports is acknowledged, although it is noteworthy that parent-proxy report has proved a reliable and valid measure of obesity-specific health-related quality of life elsewhere. ${ }^{64}$ Further research is required to understand how interventions can best promote long-term behavioural change in families.

By mapping the GOALS intervention onto the TIDieR checklist, ${ }^{39}$ this paper provides a transparent account of the intervention modifications that were necessary during the study period. Such 'teething problems' are a natural process of complex intervention implementation, ${ }^{38}$ and flexibility is important to tailor interventions to local needs. ${ }^{65}$ Yet delivery challenges are rarely acknowledged in the research literature, nor consideration given to the potential impact of modifications on intervention outcomes. In the current study, the proportion of children who reduced BMI z-score during 
GOALS increased each year $(43 \%, 63 \%$ and $80 \%$ respectively) and service audit data suggests these figures continued to rise after the study period. While there is insufficient data to link these improvements to intervention refinements, it is possible that results from the first year did not reflect the true potential of the intervention. GOALS staff turnover during the study period was low (by the final year 12/14 staff had been delivering GOALS for at least 2 years), therefore it is plausible that an increase in staff knowledge and experience positively impacted intervention delivery.

While this study provides an important insight into childhood obesity treatment in practice, some limitations must be acknowledged. The service level agreement required that GOALS was available for all children who were obese within Liverpool, therefore a randomised controlled trial was not possible. While other studies of childhood obesity treatment have employed a waiting-list control, ${ }^{719}$ GOALS was funded on a year-by-year basis and there was insufficient time to allow for participant recruitment plus two cycles of the intervention (which would be required for a waiting list design). Therefore it is acknowledged that the pre-post design provides no information about how children's BMI z-scores might have changed without intervention (although qualitative data does suggest GOALS played a role in changing family PA and dietary behaviours). Future research conducted under service level conditions should consider a non-randomised comparison group, such as children from neighbouring regions not eligible for the intervention (see ref. 35 for a discussion of the challenges of conducting research within a service delivery setting). Furthermore, there was a high attrition rate from the intervention and it is not known whether those who dropped out achieved any benefits. It was not always possible to attain reasons for drop out, but reported issues included difficulty with transport, clashes with other commitments (eg, sports clubs), and adverse life events (eg, relationship breakdown, family illness). The observed attrition rate $(48 \%)$ is comparable to that observed in other childhood obesity treatment interventions $^{66}$ and as the children who completed did not differ from the baseline population, a complete case analysis was conducted to explore the impact of the intervention for children who completed GOALS. However, it is acknowledged these children represented less than $50 \%$ of the baseline cohort therefore the current results must be interpreted with caution. Finally, the sample was predominantly White-British. Results cannot therefore be generalised to other ethnic populations living in the UK, for whom engagement with childhood obesity treatment interventions may be differentially influenced by cultural perceptions of obesity. ${ }^{67}$

\section{CONCLUSIONS}

A key strength of service evaluation is its high ecological validity and capacity to investigate intervention impact as it is delivered in practice. This study shows the GOALS childhood obesity treatment intervention supported families to change their PA and dietary behaviours, resulting in small improvements to children's BMI z-scores. Delivery challenges are inevitable when implementing a complex intervention, and it is possible the current results were diluted by early implementation difficulties. Therefore commissioners are encouraged to dedicate long-term funding to allow childhood obesity treatment interventions time to embed before evaluating their worth. ${ }^{43}$ To support the translation of evidence to practice, researchers are urged to draw on relevant reporting guidelines ${ }^{39} 6869$ to ensure transparency of intervention components, necessary modifications and evaluation methods. Doing so will enable comparison between studies and provide vital information for policymakers and practitioners wishing to implement a childhood obesity treatment intervention in their locality.

Twitter Follow the Physical Activity Exchange at @LJMU_PAEx

Acknowledgements The authors would like to thank Liz Lamb, Jamuna Acharya and Ruwan De Soysa for their support in the strategic management of the GOALS project; Nicola Eccles, Shirley Judd, Lisa Newson, Hazel Cheung and Phil Casey for their contribution to the early development of the GOALS intervention; and not least the families who participated in GOALS, staff who delivered the intervention, school health team who provided medical support and schools who provided use of their facilities.

Contributors PMW conducted the study as part of her doctoral degree and drafted the article. NTC and LD conceived the study, secured funding and contributed to the analysis and interpretation of data. NTC managed the overall project and supervised PMW's doctoral programme, along with RCM and ZK who both contributed to the analysis and interpretation of data. KP, SO, JH and LJS designed the intervention and worked alongside PMW to develop it according to ongoing feedback. All authors critically reviewed and contributed to the writing of the paper.

Funding Funding for this study was received from the Neighbourhood Renewal Fund and the Area Based Grant as part of Liverpool's Taste for Health Strategy (Liverpool City Council and Liverpool PCT).

Competing interests PMW, KP, SO, JH and LJS were employed by Liverpool John Moores University to design, deliver and evaluate the GOALS intervention.

Ethics approval Ethical approval was received from the Liverpool NHS Paediatric Research Ethics Committee [05/Q1502/28]. Written informed consent was obtained from parents/carers, and written assent from children over 8 years and deemed capable of understanding.

Provenance and peer review Not commissioned; externally peer reviewed.

Data sharing statement There is descriptive data available for the overweight siblings who completed the intervention, plus other measures that were piloted with subgroups of the study population (eg, waist-to-height ratio). The authors are willing to share this data with practitioners or researchers interested in the evaluation of family-based childhood obesity treatment interventions (please request from PMW, p.m.watson@ljmu.ac.uk).

Open Access This is an Open Access article distributed in accordance with the Creative Commons Attribution Non Commercial (CC BY-NC 4.0) license, which permits others to distribute, remix, adapt, build upon this work noncommercially, and license their derivative works on different terms, provided the original work is properly cited and the use is non-commercial. See: http:// creativecommons.org/licenses/by-nc/4.0/

\section{REFERENCES}

1. Craig R, Mindell J, eds. Health survey for England 2012: health, social care and lifestyles. Leeds: Health and Social Care Information Centre, 2013. 
2. Griffiths LJ, Parson TJ, Hill AJ. Self-esteem and quality of life in obese children and adolescents: a systematic review. Int $J$ Pediatr Obes 2010;5:282-304

3. Shultz SP, Anner J, Hills AP. Paediatric obesity, physical activity and the musculoskeletal system. Obes Rev 2009;10:576-82.

4. Singh AS, Mulder C, Twisk JWR, et al. Tracking of childhood overweight into adulthood: a systematic review of the literature. Obes Rev 2008;9:474-88.

5. Prospective Studies Collaboration. Body-mass index and cause-specific mortality in 900000 adults: collaborative analyses of 57 prospective studies. Lancet 2009;373:1083-96.

6. Oude Luttikhuis $\mathrm{H}$, Baur L, Jansen $\mathrm{H}$, et al. Interventions for treating obesity in children (review): the Cochrane Collaboration. Wiley, 2009.

7. Sacher PM, Kolotourou M, Chadwick P, et al. Randomized controlled trial of the MEND program: a family-based community intervention for childhood obesity. Obesity 2010;18(Suppl 1):S62-8.

8. Teder M, Mörelius E, Bolme P, et al. Family-based behavioural intervention programme for obese children: a feasibility study. $B M J$ Open 2012;2:e000268

9. Watson PM, Dugdill L, Pickering $\mathrm{K}$, et al. A whole family approach to childhood obesity management (GOALS): relationship between adult and child BMl change. Ann Hum Biol 2011;38:445-52.

10. Murdoch N, Payne N, Samani-Radia D, et al. Family-based behavioural management of childhood obesity: service evaluation of a group programme run in a community setting in the United Kingdom. Eur J Clin Nutr 2011:65:764-7.

11. Coppins DF, Margetts BM, Fa JL, et al. Effectiveness of a multi-disciplinary family-based programme for treating childhood obesity (The Family Project). Eur J Clin Nutr 2011;65:903-9.

12. Bandura A. Social foundations of thought and action: a social-cognitive theory. New Jersey: Prentice Hall, 1986.

13. Taylor WC, Baranowski T, Sallis JF. Family determinants of childhood physical activity: a social-cognitive model. In: Dishman RK, ed. Advances in exercise adherence. Champaign, IL: Human Kinetics, 1994:319-42.

14. Biddle SJH, Atkin AJ, Cavill N, et al. Correlates of physical activity in youth: a review of quantitative systematic reviews. Int Rev Sport Exerc Psychol 2011;4:25-49.

15. Pearson N, Biddle SJH, Gorely T. Family correlates of fruit and vegetable consumption in children and adolescents: a systematic review. Public Health Nutr 2008;12:267-83.

16. Faith MS, Van Horn L, Appel LJ, et al. Evaluating parents/carers and adult caregivers as "Agents of Change" for treating obese children evidence for parent behavior change strategies and research gaps: a scientific statement from the American Heart Association. Circulation 2012;125:1186-207.

17. Golan M, Weizman A, Apter A, et al. Parents/carers as the exclusive agents of change in the treatment of childhood obesity. Am J Clin Nutr 1998;67:1130-8.

18. Golley RK, Magarey AM, Baur LA, et al. Twelve-month effectiveness of a parent-led, family-focused weight-management program for pre-pubertal children: a randomized, controlled trial. Pediatrics 2007:119:517-25.

19. Croker H, Viner RM, Nicholls D, et al. Family-based behavioural treatment of childhood obesity in a UK national health service setting: randomized controlled trial. Int J Obes (Lond) 2012;36:16-26.

20. Goldfield GS, Epstein LH, Kilanowski CK, et al. Cost-effectiveness of group and mixed family-based treatment for childhood obesity. Int $J$ Obes Relat Metab Disord 2001;25:1843-9.

21. Berry D, Savoye M, Melkus G, et al. An intervention for multi-ethnic obese parents/carers and overweight children. Appl Nurs Res 2007;20:63-71.

22. O'Dwyer MV, Fairclough SJ, Knowles Z, et al. Effect of a family focused active play intervention on sedentary time and physical activity in preschool children. Int J Behav Nutr Phys Act 2012;9:117.

23. Morgan PJ, Lubans DR, Callister R, et al. The 'Healthy Dads, Healthy Kids' randomized controlled trial: efficacy of a healthy lifestyle program for overweight fathers and their children. Int $J$ Obes (Lond) 2011;35:436-47.

24. Twiddy M, Wilson I, Bryant $\mathrm{M}$, et al. Lessons learned from a family-focused weight management intervention for obese and overweight children. Public Health Nutr 2012;15:1310-17.

25. O'Dea JA. Evidence for a self-esteem approach in the prevention of body image and eating problems among children and adolescents. Eat Disord 2004;12:225-39.

26. Walker Lowry K, Sallinen BJ, Janicke DM. The effects of weight management programs on self-esteem in pediatric overweight populations. J Pediatr Psychol 2007;32:1179-95.
27. Walker LLM, Gately PJ, Bewick BM, et al. Children's weight-loss camps: psychological benefit or jeopardy? Int J Obes Relat Metab Disord 2003;27:748-54

28. Epstein LH, Wrotniak BH. Future directions for pediatric obesity treatment. Obesity 2010;18(Suppl 1):S8-12.

29. Upton P, Taylor C, Erol R, et al. Family-based childhood obesity interventions in the UK: a systematic review of published studies. Community Pract 2014;87:25-9.

30. Smith LR, Chadwick P, Radley D, et al. Assessing the short-term outcomes of a community-based intervention for overweight and obese children: the MEND 5-7 programme. BMJ Open 2013;3: e002607.

31. Upton P, Taylor CE, Peters DM, et al. The effectiveness of local child weight management programmes: an audit study. Child Care Health Dev 2012;39:125-33.

32. Newson L, Povey R, Casson A, et al. The experiences and understandings of obesity: families' decisions to attend a childhood obesity intervention. Psychol Health 2013;28:1287-305.

33. Banks J, Cramer H, Sharp DJ, et al. Identifying families' reasons for engaging or not engaging with childhood obesity services: a qualitative study. J Child Health Care 2013;18:101-10.

34. Staniford LJ, Breckon JD, Copeland RJ, et al. Key stakeholders' perspectives towards childhood obesity treatment: a qualitative study. J Child Health Care 2011;15:230-44.

35. Watson PM, Dugdill L, Murphy R, et al. Moving forward in childhood obesity treatment: a call for translational research. Health Educ $J$ 2013;72:230-9.

36. Bryant M, Farrin A, Christie D, et al. Results of a feasibility randomised controlled trial (RCT) for WATCH IT: a programme for obese children and adolescents. Clin Trials 2011;8:755-64.

37. Klesges LM, Williams NA, Davis KS, et al. External validity reporting in behavioral treatment of childhood obesity. Am J Prev Med 2012;42:185-92.

38. Craig P, Dieppe P, Macintyre S, et al. Developing and evaluating complex interventions: new guidance. Medical Research Council, 2008. http://www.mrc.ac.uk/complexinterventionsguidance

39. Hoffman TC, Glasziou PP, Boutron I, et al. Better reporting of interventions: template for intervention description and replication (TIDieR) checklist and guide. BMJ 2014;348:g1687.

40. Dugdill L, Stratton GS, Watson PM. Developing the evidence base for physical activity interventions. In: Dugdill L, Crone D, Murphy $R$ eds. Physical activity and health promotion: evidence-based approaches to practice. Oxford: Wiley-Blackwell, 2009:60-81

41. Stratton GS, Watson PM. Young people and physical activity. In: Dugdill L, Crone D, Murphy R, eds. Physical activity and health promotion: evidence-based approaches to practice. Oxford: Wiley-Blackwell, 2009:150-69.

42. Cole TJ, Freeman JV, Preece MA. Body mass index reference curves for the UK, 1990. Arch Dis Child 1995;73:25-9.

43. National Institute for Health and Care Excellence. Managing overweight and obesity among children and young people. Public Health Guidance 47. 2013. http://guidance.nice.org.uk/PH47

44. Taylor S, Hackett AF Stratton G, et al. Sports Linx: improving the health and fitness of Liverpool's youth. Educ Health 2004;22:3-7.

45. NHS Choices. Healthy eating. http://www.nhs.uk/Livewell/ healthy-eating/Pages/Healthyeating.aspx (accessed 4 Oct 2013).

46. Liverpool City Council. Population statistics. http://liverpool.gov.uk/ council/key-statistics-and-data/data/population/ (accessed 14 Nov 2014).

47. Liverpool City Council. The Index of Multiple Deprivation 2010: a Liverpool analysis. 2011. http://liverpool.gov.uk/council/key-statisticsand-data/indices-of-deprivation/ (accessed 10 Nov 2014).

48. Boddy LM, Hackett AF, Stratton G. Changes in fitness, body mass index and obesity in 9-10-year-olds. J Hum Nutr Diet 2010;23:254-9.

49. Health and Social Care Information Centre. National Child Measurement Programme: England, 2012/13 school year. 2013. http://www.hscic.gov.uk/catalogue/PUB13115

50. Scottish Intercollegiate Guidelines Network. Management of obesity in children and young people: a national clinical guideline. Edinburgh: SIGN, 2003.

51. National Institute for Health and Clinical Excellence. Obesity: guidance on the prevention, identification, assessment and management of overweight and obesity in adults and children. Clinical guideline 43. 2006. http://www.nice.org.uk/guidance/cg43

52. Leigh-Hunt N, Rudolf M. A review of local practice regarding investigations in children attending obesity clinics and a comparison of the results with other studies. Child Care Health Dev 2007;34:55-8. 
53. Pan H, Cole TJ. LMS Growth: a Microsoft Excel add-in to access growth references based on the LMS method. http://www. healthforallchildren.com/?product=Imsgrowth

54. Harter S. Manual for the self-perception profile for children. Denver, CO: University of Denver, 1985.

55. Office for National Statistics. Indices of Deprivation 2007 for Super Output Areas. 2007. http://www.neighbourhood.statistics.gov.uk/ dissemination/ (accessed 16 Nov 2014).

56. Rudolf M, Christie D, McElhone S, et al. WATCH IT: a community based programme for obese children and adolescents. Arch Dis Child 2006;91:736-9.

57. Sabin MA, Shield JPH. Clinical significance vs statistical significance in childhood obesity weight management programmes: letter to the editor. Arch Dis Child 2006;91:736.

58. Reinehr T, De Sousa G, Toschke AM, et al. Long-term follow-up of cardiovascular disease risk factors in children after an obesity intervention. Am J Clin Nutr 2006;84:490-6.

59. Kolsgaard ML, Joner G, Brunborg C, et al. Reduction in BMl z-score and improvement in cardiometabolic risk factors in obese children and adolescents. The Oslo Adiposity Intervention Study-a hospital/ public health nurse combined treatment. BMC Pediatr 2011;11:47.

60. Speiser PW, Rudolf MC, Anhalt $\mathrm{H}$, et al; Obesity Consensus Working Group. Childhood Obesity. J Clin Endocrinol Metab 2005;90:1871-87.

61. Sahota P, Rudolf MC, Dixey R, et al. Randomised controlled trial of primary school based intervention to reduce risk factors for obesity. BMJ 2001;323:1029-32.
62. Marx RD, Neumark-Sztainer D. Question: what can we do to help parents/carers raise children with a healthy weight and a healthy body image? Eat Disord 2005;13:491-5.

63. Prochaska JO, Velicer WF. The transtheoretical model of health behavior change. Am J Health Promot 1997; 12:38-48.

64. Modi AC, Zeller MH. Validation of a parent-proxy, obesity-specific quality-of-life measure: sizing them up. Obesity 2008;16:2624-33.

65. Øen G, Stormark KM. Participatory action research in the implementing process of evidence-based intervention to prevent childhood obesity: project design of the "Healthy Future" study. J Obes 2013;2013:437206.

66. Skelton JA, Beech BM. Attrition in paediatric weight management: a review of the literature and new directions. Obes Rev 2010;12: e273-81.

67. Trigwell J, Watson PM, Murphy RC, et al. Ethnic differences in parental attitudes and beliefs about being overweight in childhood. Health Educ J 2014;73:179-91.

68. Des Jarlais DC, Lyles C, Crepaz N; TREND Group. Improving the reporting quality of nonrandomized evaluations of behavioral and public health interventions: the TREND Statement. Am J Public Health 2004;94:361-6.

69. Michie S, Ashford S, Sniehotta FF, et al. A refined taxonomy of behaviour change techniques to help people change their physical activity and healthy eating behaviours: the CALO-RE taxonomy. Psychol Health 2011;26:1479-98. 